\title{
Knowledge, attitude, and practice about rabies prevention and control: A community survey in Nepal
}

\author{
Pushkar Pal ${ }^{1,2}$, Adisorn Yawongsa1(i), Tej Narayan Bhusal3 (iD, Rajendra Bashyal4 ${ }^{(i)}$ and Theera Rukkwamsuk ${ }^{1}$ (i) \\ 1. Department of Large Animal and Wildlife Clinical Sciences, Faculty of Veterinary Medicine, Kasetsart University, \\ Nakhon Pathom 73140, Thailand; 2. Department of Veterinary Pathology and Clinics, Agriculture and Forestry University, \\ Nepal; 3. Department of Plant Breeding and Genetics, Agriculture and Forestry University, Nepal; 4. Department of \\ Anatomy, Physiology and Biochemistry, Agriculture and Forestry University, Nepal. \\ Corresponding author: Theera Rukkwamsuk, e-mail: fvettrr@ku.ac.th \\ Co-authors: PP: drpushkar_pal@hotmail.com,AY: fvetady@ku.ac.th,TNB: tnbhusal@afu.edu.np, \\ RB: rajendrabashyal@gmail.com \\ Received: 04-10-2020, Accepted: 01-03-2021, Published online: 17-04-2021
}

doi: www.doi.org/10.14202/vetworld.2021.933-942 How to cite this article: Pal P, Yawongsa A, Bhusal TN, Bashyal R, Rukkwamsuk T (2021) Knowledge, attitude, and practice about rabies prevention and control: A community survey in Nepal, Veterinary World, 14(4): 933-942.

\begin{abstract}
Background and Aim: Rabies is a fatal zoonosis caused by RNA virus belonging to genus Lyssavirus. Nepal is one of the endemic countries in South Asia for rabies. This study was conducted to better understand the knowledge, attitude, and practice (KAP) of Nepalese community toward rabies across five developmental zones of the country.

Materials and Methods: The cross-sectional study was carried out by face-to-face interview using structured questionnaires among 5000 respondents of five cities representing each of the five developmental regions of Nepal by adopting random cluster sampling procedure. The respondents were classified into four categories, including gender, age, education, and social status. The responses for KAP variables were analyzed using descriptive and Chi-square test.
\end{abstract}

Results: The male and younger age respondents with higher education and social status were found more knowledgeable than their counterparts in terms of knowledge variables, including cause of rabies, mode of transmission, clinical signs, treatment, and preventive measures of this fatal disease. Similar findings were observed for attitude and practice variables such as vaccination practice, dog sterilization, health-seeking behavior, first aid practice, and use of first aid materials after dog bites. Some respondents in elderly age group still preferred to use traditional and local methods, which were application of turmeric powder and shrubs to cure dog bites rather than seeking medical facilities.

Conclusion: There is a strong need for rabies awareness programs in the community targeting females, school, and collegelevel students, older age groups, and economically marginalized communities. The awareness materials need to focus on particular topics such as the risk of rabies, modes of transmission, the importance of first aid, health-seeking behavior following dog bite injuries, and practice preventive measures for their pets and community dogs.

Keywords: communities, developmental zones, knowledge, attitude and practice survey, Nepal, rabies.

\section{Introduction}

Rabies, caused by a negative-stranded RNA virus within the Lyssavirus genus of the Rhabdoviridae family, is one of the oldest diseases accounting for significant public health issues [1]. The disease can be lethal to humans and animals once clinical symptoms have developed [2]. Although the disease is preventable, approximately 59000 people died of rabies every year, with $95 \%$ of these cases occurring in the Asian and African regions [3]. Despite considerable efforts, including extended control plans and general awareness programs to contain rabies infection, over 35000 cases still occur in Asia [1]. The primary source of animal and human rabies in the Asian continent is the bite of rabies-infected dogs, causing up to $95 \%$ of cases [4].

Copyright: Pal, et al. Open Access. This article is distributed under the terms of the Creative Commons Attribution 4.0 International License (http://creativecommons.org/licenses/by/4.0/), which permits unrestricted use, distribution, and reproduction in any medium, provided you give appropriate credit to the original author(s) and the source, provide a link to the Creative Commons license, and indicate if changes were made. The Creative Commons Public Domain Dedication waiver (http://creativecommons.org/ publicdomain/zero/1.0/) applies to the data made available in this article, unless otherwise stated.
Nepal is a small Himalayan country in South Asia. The Nepal's southern plain areas, connected to the Indian border, grant restriction-free movement of animals and human beings, which causes rabies to be endemic in both countries [5]. A report described the open border facilitates in infection transmission, including rabies [6]. A similar report from Bhutan described that the higher number of rabies cases were recorded in the areas bordered with India [7]. A study carried out by Dog's Trust, UK, in 2014, reported a higher number of rabies cases in Indo-Bhutan and Indo-Nepal borders than in the other parts of both countries (Figure-1). Rabies has rapidly become a highly relevant subject area for research; due to frequent outbreaks typically affecting domestic animals and humans. A study conducted in 2011 revealed that one hundred and fifty human deaths and a similar number of livestock deaths occurred every year in Nepal [8]. According to that study, the situation of rabies in the South Asian Association of Regional Cooperation is summarized in Table-1. In Nepal, the deaths resulting from rabies are likely to be underreported due to 


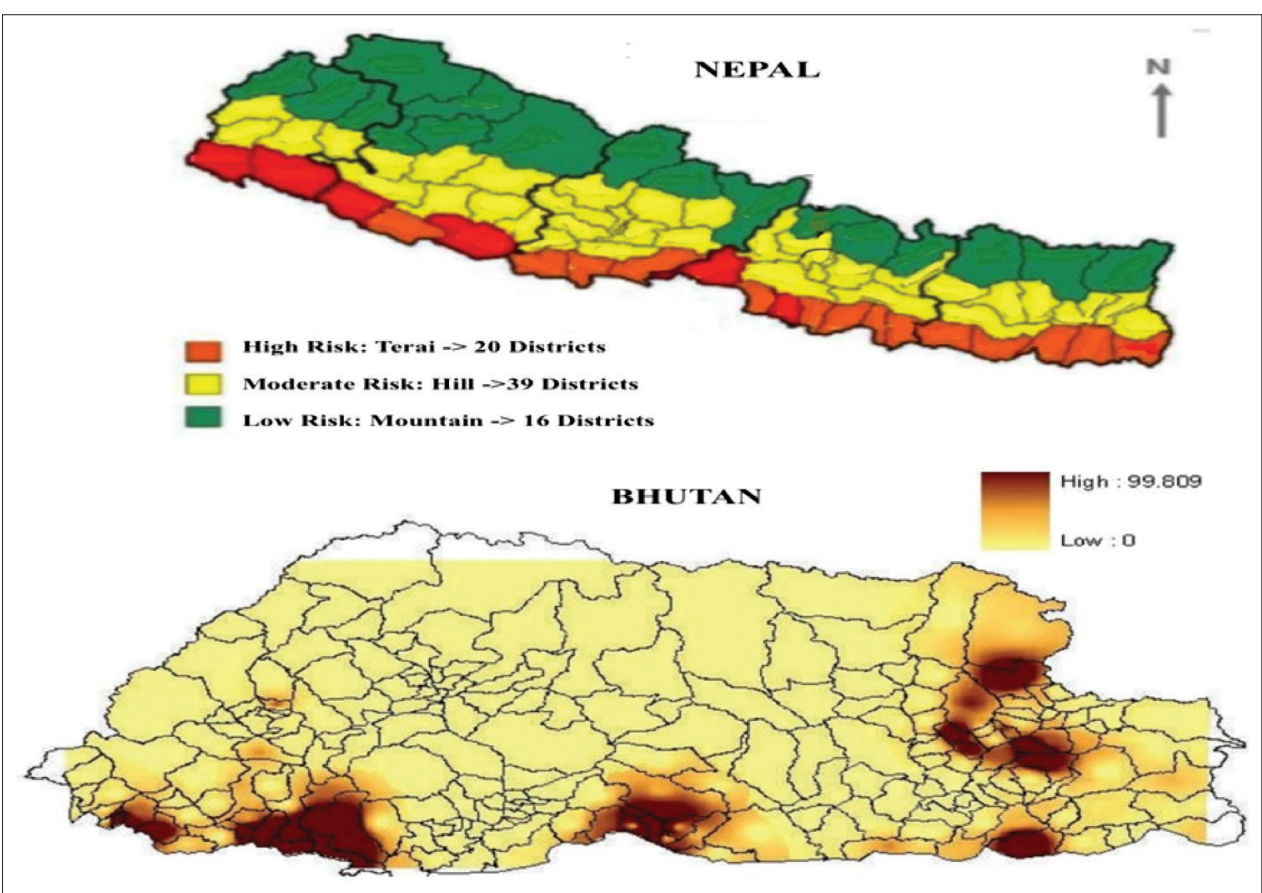

Figure-1: Rabies cross-border issue [Source: Annual Bulletin of Dogs Trust-2014].

its topography, weak surveillance system, and inadequate knowledge about rabies [6]. There is a strong need for evidence-based research on epidemiology of rabies and community knowledge, attitude, and practice (KAP) toward rabies to plan the intervention programs of this disease [9].

The KAP study has been extensively used in communities to understand their status toward infectious diseases across the world. The KAP study has also become helpful in comprehending the disease burden [10]. Moreover, the KAP study has become an integral part of the rabies control and elimination in both developed and developing worlds. In recent years, the Government of Nepal (GoN) has shown solidarity to eliminate rabies by 2030 . However, there is no concrete policy and program based on the research. Although rabies is well known as an infectious disease and a burden in Nepal, it has not received significant attention for research. Furthermore, there is a lack of clarity on the available data due to limited studies [11].

Therefore, this study was designed to better understanding the community's knowledge, attitude and practice about rabies in Nepal. These study findings would help concerned agencies, mainly the GoN, to effectively build up the rabies control plans.

\section{Materials and Methods}

\section{Ethical approval}

Ethical approval was not necessary for this study. However, individual consent was taken from the respondents who participated in the study.

\section{Study design, period and area}

A community-based cross-sectional survey was conducted from November 2018 to August 2019
Table-1: Situation of rabies in Nepal at South Asian Association of Regional Cooperation Region.

\begin{tabular}{lccc}
\hline Countries & $\begin{array}{c}\text { Estimated } \\
\text { cases }\end{array}$ & $\begin{array}{c}\text { Human cases, \% of dog bite } \\
\text { per } \mathbf{1 0 0 0 0 0}\end{array}$ \\
\hline Afghanistan & $2000-3000$ & 5.7 & $\mathrm{~N} / \mathrm{A}$ \\
Bangladesh & $1500-2000$ & 1.5 & 95 \\
Bhutan & $<10$ & 0.28 & 99 \\
India & $18000-20000$ & 3 & $>95$ \\
Nepal & 150 & 0.21 & 98.5 \\
Sri Lanka & $<50$ & 0.26 & 95 \\
Pakistan & $2000-5000$ & 1.3 & $>90$ \\
\hline
\end{tabular}

Source: WHO, 2013

in the five developmental zones of Nepal (recently changed to states), namely: Eastern, Central, West, Mid-west, and Far-west. The study was performed in the headquarter districts of respective developmental regions (Figure-2), inhabiting 602,733 people $(2.46 \%$ of Nepalese population according to 2011 national census). These study areas have been assumed to be more advanced in terms of education, physical facilities, and human resource indices in their respective regions.

\section{Survey method}

The study surveyed 5000 participants. One thousand participants (500 males and 500 females) were randomly selected from each of the developmental regions for the face-to-face interview. The random cluster sampling method was adopted for this purpose. The survey participants were categorized into gender, age, level of education, and social status. The study had a uniform sample population in the gender category and heterogeneous population in the remaining categories. Table- 2 presents the demographic characteristics of our study population. 


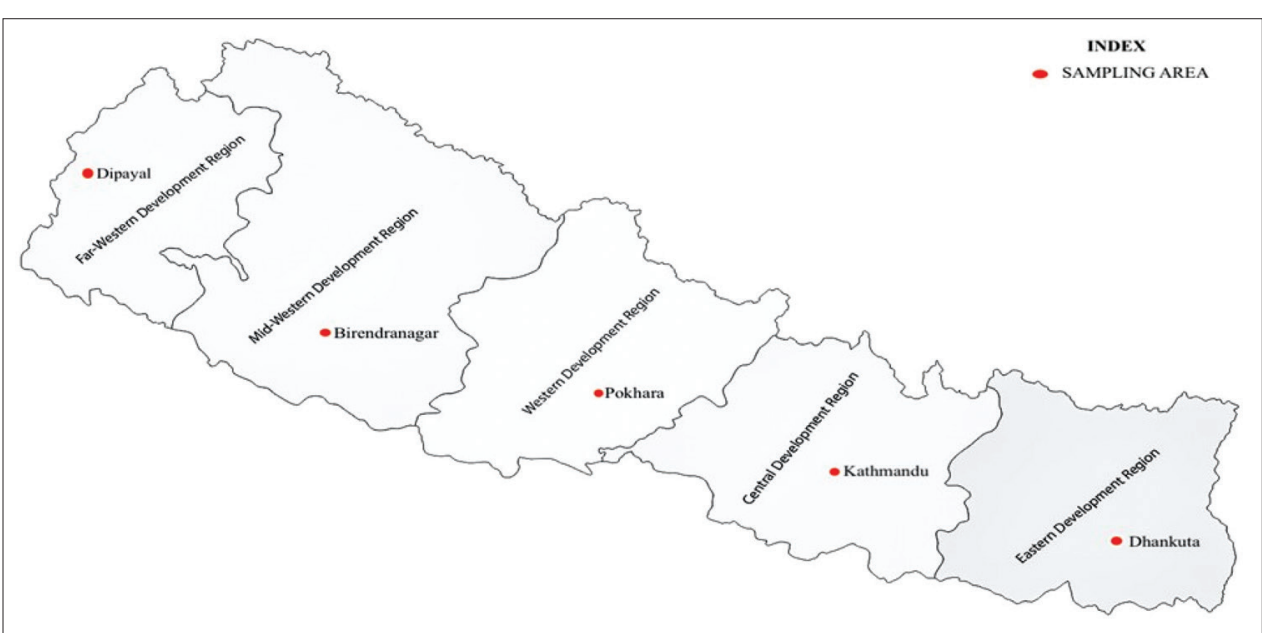

Figure-2: The sampling locations of knowledge-attitude-practice study.

Table-2: Demographic characteristic of the survey respondents.

\begin{tabular}{llc}
\hline Variables & Characteristics & n (\%) \\
\hline Gender & Male & $2500(50.0)$ \\
& Female & $2500(50.0)$ \\
Age group & $\leq 35$ & $3130(62.6)$ \\
\multirow{2}{*}{ Education level } & $\geq 36$ & $1870(37.4)$ \\
& School/college & $4097(81.9)$ \\
Socio-economic status & University & $903(18.1)$ \\
& Upper/middle & $2265(45.3)$ \\
& Lower & $2735(54.7)$ \\
\hline
\end{tabular}

\section{Sampling and interview procedure of households}

To assess the KAP, the selected locations were further divided into sub-areas with the help of local village leaders and residents. The residential areas were divided into neighborhoods based on the household's median income and education level. The KAP study was then conducted in each neighborhood. A door-to-door survey was conducted using a rolling sample method [12]. According to this method, the first selected household provides information about the next available house in the area or within the neighborhood, until the target number of household respondents was interviewed in the study area. However, it was guaranteed that representative samples were selected from all the selected locations. One adult person $(>18$ years of age) from each chosen household/family was interviewed face-to-face either in the morning or evening. The selected person was informed about the purpose of the study and that participation was voluntary. Data received from the respondents would be kept confidential. The interview was administered in the national language, and later the answers were translated into English.

\section{Questionnaire design}

A well-structured questionnaire was designed to assess the KAP about rabies. The questionnaire was partly adapted from similar studies conducted previously [12,13]. Tables-3 and 4 demonstrate the determinants of KAP.
Table-3: Assessment of rabies knowledge.

\begin{tabular}{ll}
\hline Variables & Response \\
\hline Cause of rabies & Microorganism \\
& Non microorganisms \\
Ways of transmission & Cat \\
& Dog \\
& Wild animals \\
& Rodents \\
& No answer \\
& Salivation \\
What are the symptoms of rabies & Altered personality \\
& Hydrophobia \\
& Aerophobia \\
& Don't know \\
& Yes \\
Is the disease treatable & No \\
& Yes \\
Is the disease fatal & No \\
& Yes \\
Is the disease preventable & No \\
& \\
\hline
\end{tabular}

\section{Data management and analysis}

The questionnaire responses were transferred to Excel (Microsoft Excel, 2010, Microsoft Corp., Redmond, WA, USA) and made compatible with subsequent analysis using $\mathrm{R}$ studio. A Chi-square test was performed to test the association of the studied variables related to KAP. Odds ratios were calculated to describe the association of each variable (gender, age group, education level, and socio-economic status) and the questionnaire outcomes for KAP. Similarly, descriptive analysis was also performed to analyze the multiple responses.

\section{Results}

\section{Knowledge about rabies transmission}

The questionnaire had multiple choice answers to assess the knowledge on mode of transmission (Table-5). The descriptive analysis discovered that $55-70 \%$ of the respondents had a knowledge about the possible transmission route of rabies by the dog. However, all respondents had fairly less knowledge on other ways of rabies transmission. This finding would suggest that respondents had low level of knowledge about the ways of rabies transmission other than dogs. 
This knowledge gap in communities could be a risk factor for disease control programs.

\section{Knowledge about rabies symptoms}

The study discovered that the knowledge on clinical signs were meager in all the studied respondents (Table-6). The responses received for the altered personality, salivation, and hydrophobia, do not know and aerophobia were $36-48 \%, 29-37 \%, 6-19 \%, 5-16 \%$, and $0.8-7 \%$, respectively. The study confirmed that the community had very less knowledge concerning the clinical manifestation of rabies. Our findings hinted that the gap in the knowledge about clinical signs could be considered as a potential risk factor for the rabies elimination programs.

\section{Analysis on knowledge about rabies according to gender and age}

Analysis of responses relating to rabies knowledge among various determinant variables

Table-4: Assessment of attitude and practice toward rabies.

\begin{tabular}{ll}
\hline Variables & Response \\
\hline Have you heard about rabies? & Yes \\
& No \\
Do you vaccinate your pets/community & Yes \\
dogs against rabies? & No \\
Are you familiar with the vaccination/ABC & Yes \\
campaigns organized by government?/ & No \\
Non-profits for Free-roaming dogs (FRD $)^{\text {b }}$ ? & \\
What would you do when you get bitten & Seek \\
by rabid animals/wild lives/pets & medical care \\
& Traditional \\
& healer \\
Do you practice first aid after getting & Do nothing \\
bitten by rabid animals? & Yes \\
Which first aid materials do you practice? & No \\
& Soap water \\
& Herbal \\
& products \\
& Traditional \\
& methods \\
\hline
\end{tabular}

animal birth control, bree-roaming dog is presented in Table-7. Female populations were less likely to know about the determinants of rabies knowledge than their counterparts. Similarly, older ( $\geq 36$ years) respondents were less knowledgeable than the younger group.

Analysis on knowledge about rabies according to education and socio-economic status

In this category, respondents with university-level education were more knowledgeable than the respondents with school/college level education (Table-8). Similarly, respondents from upper/middle class were more familiar about the rabies knowledge than those from the lower-class participants. The study confirmed that rabies knowledge is influenced by the level of education and social class.

\section{Analysis of attitude and practice according to gender and age}

The present study confirmed the findings of the attitude and practices of respondents (Table-9). Both male and female respondents almost equally vaccinated their pets/community dogs against rabies, sought medical care when bitten by suspected rabid animals, and used soap water to wash bite-wound. In the age category, older respondents were less likely to have a positive attitude and good practices including vaccinated their pets/community dogs against rabies, sought medical care when bitten by rabid animals, did first aid practice, and used soap water to wash bite-wound. In contrast, they were more likely to familiar with the vaccination/Animal birth control (ABC) campaign for free-roaming dogs (FRD) organized by the government or non-profits organizations. From these results, it was clear that the older age group seemed to have poor practice and attitude toward rabies compared to the lower age group. For successful elimination and control programs, all the community segments should adopt an appropriate attitude and practice toward the recommended measures.

Table-5: Multiple choice responses (\%) about rabies transmission.

\begin{tabular}{|c|c|c|c|c|c|c|c|c|}
\hline \multirow[t]{2}{*}{ Transmission } & \multicolumn{2}{|c|}{ Gender } & \multicolumn{2}{|c|}{ Age } & \multicolumn{2}{|c|}{ Education } & \multicolumn{2}{|c|}{ Socio-economic status } \\
\hline & Male & Female & $\leq 35$ & $\geq 36$ & School/college & University & Lower & Upper/Middle \\
\hline Dog & 65.4 & 58.88 & 58.68 & 68.05 & 62.52 & 60.03 & 57.91 & 68.35 \\
\hline Cat & 15.04 & 17.4 & 17.49 & 10.57 & 14.10 & 20.72 & 16.67 & 16.07 \\
\hline Wild animals & 6.52 & 7.44 & 8.18 & 5.51 & 5.49 & 12.30 & 8.48 & 4.76 \\
\hline Rodents & 6.24 & 5.72 & 4.33 & 9.71 & 6.12 & 6.95 & 6.21 & 6.18 \\
\hline Don't know & 6.80 & 10.56 & 11.23 & 6.18 & 11.67 & - & 11.80 & 4.61 \\
\hline
\end{tabular}

Table-6: Multiple choice responses (\%) about rabies symptoms.

\begin{tabular}{|c|c|c|c|c|c|c|c|c|}
\hline \multirow[t]{2}{*}{ Transmission } & \multicolumn{2}{|c|}{ Gender } & \multicolumn{2}{|c|}{ Age } & \multicolumn{2}{|c|}{ Education } & \multicolumn{2}{|c|}{ Socio-economic status } \\
\hline & Male & Female & $\leq 35$ & $\geq 36$ & School/college & University & Lower & Upper/Middle \\
\hline Salivation & 33.28 & 32.84 & 33.84 & 29.15 & 31.84 & 37.18 & 37.09 & 31.94 \\
\hline Hydrophobia & 11.08 & 5.80 & 6.64 & 6.76 & 5.85 & 17.76 & 6.14 & 19.23 \\
\hline Aerophobia & 2.28 & 0.84 & 1.65 & 1.71 & 0.75 & 4.44 & 0.58 & 6.98 \\
\hline Altered personality & 45.00 & 44.12 & 45.47 & 43.53 & 48.25 & 30.80 & 44.20 & 36.38 \\
\hline Don't know & 16.40 & 16.40 & 12.37 & 14.28 & 13.27 & 9.80 & 18.46 & 5.43 \\
\hline
\end{tabular}


Table-7: Association of gender or age and the responses toward rabies knowledge.

\begin{tabular}{|c|c|c|c|c|c|c|c|c|c|}
\hline \multirow[t]{2}{*}{ Variables } & \multirow[t]{2}{*}{ Number } & \multicolumn{2}{|r|}{ Gender } & \multirow[t]{2}{*}{$\chi^{2}$-value } & \multirow[t]{2}{*}{ p-value } & \multicolumn{2}{|r|}{ Age } & \multirow[t]{2}{*}{$\chi^{2}$-value } & \multirow[t]{2}{*}{ p-value } \\
\hline & & Male & Female & & & $\leq 35$ & $\geq 36$ & & \\
\hline \multicolumn{4}{|c|}{ Availability of treatment } & 36.35 & $<0.001$ & & & 745.06 & $<0.001$ \\
\hline Yes & 3561 & 1877 & 1684 & & & 2652 & 909 & & \\
\hline No & 1439 & 623 & 816 & & & 478 & 961 & & \\
\hline \multicolumn{2}{|c|}{ OR $(95 \% \mathrm{CI})$} & 1.0 & $0.68(0.61-0.77)$ & & & 1.0 & $0.17(0.15-0.19)$ & & \\
\hline \multicolumn{2}{|c|}{ Rabies is fatal } & & & 13.59 & 0.0002 & & & 924.17 & $<0.001$ \\
\hline Yes & 3778 & 1945 & 1833 & & & 2812 & 966 & & \\
\hline $\begin{array}{l}\text { No/don't } \\
\text { know }\end{array}$ & 1222 & 555 & 667 & & & 318 & 904 & & \\
\hline \multicolumn{2}{|c|}{$\begin{array}{l}\text { know } \\
\text { OR }(95 \% \text { CI })\end{array}$} & 1.0 & $0.78(0.69-0.89)$ & & & 1.0 & $0.12(0.10-0.14)$ & & \\
\hline \multicolumn{2}{|c|}{ Preventive measures } & & & 8.64 & 0.003 & & & 764.59 & $<0.001$ \\
\hline Yes & 4279 & 2176 & 2103 & & & 3011 & 1268 & & \\
\hline No & 721 & 324 & 397 & & & 119 & 602 & & \\
\hline \multicolumn{2}{|c|}{ OR $(95 \% \mathrm{CI})$} & 1.0 & $0.79(0.67-0.92)$ & & & 1.0 & $0.08(0.07-0.10)$ & & \\
\hline
\end{tabular}

$\mathrm{CI}=$ Confidence interval, $\mathrm{OR}=$ Odds ratio

Table-8: Association of education or socio-economic status and the responses on rabies knowledge.

\begin{tabular}{|c|c|c|c|c|c|c|c|c|c|}
\hline \multirow[t]{2}{*}{ Variables } & \multirow[t]{2}{*}{ Number } & \multicolumn{2}{|c|}{ Education } & \multirow[t]{2}{*}{$\chi^{2}$-value } & \multirow[t]{2}{*}{ p-value } & \multicolumn{2}{|c|}{ Socio-economic status } & \multirow[t]{2}{*}{$\chi^{2}$-value } & \multirow[t]{2}{*}{ p-value } \\
\hline & & School/college & University & & & Lower & Upper/middle & & \\
\hline \multicolumn{4}{|c|}{ Availability of treatment } & 219.45 & $<0.001$ & & & 345.85 & $<0.001$ \\
\hline Yes & 3561 & 2674 & 887 & & & 1645 & 1916 & & \\
\hline No & 1439 & 1345 & 94 & & & 1081 & 358 & & \\
\hline \multicolumn{2}{|c|}{ OR $(95 \% \mathrm{CI})$} & 1.0 & $4.73(3.81-5.95)$ & & & 1.0 & $3.52(3.07-4.03)$ & & \\
\hline \multicolumn{2}{|c|}{ Rabies is fatal } & & & 2.03 & 0.15 & & & 242.54 & $<0.001$ \\
\hline Yes & 3778 & 2979 & 799 & & & 1831 & 1947 & & \\
\hline know & 1222 & 940 & 282 & & & 904 & 318 & & \\
\hline OR $(95 \%$ & CI) & 1.0 & $0.89(0.77-1.04)$ & & & 1.0 & $3.02(2.62-3.49)$ & & \\
\hline \multicolumn{2}{|c|}{ Preventive measures } & & & 3.78 & 0.05 & & & 63.60 & $<0.001$ \\
\hline Yes & 4279 & 3334 & 945 & & & 2242 & 2037 & & \\
\hline No & 721 & 585 & 136 & & & 493 & 228 & & \\
\hline \multicolumn{2}{|c|}{ OR $(95 \% \mathrm{CI})$} & 1.0 & $1.22(1.00-1.49)$ & & & 1.0 & $1.96(1.66-2.33)$ & & \\
\hline
\end{tabular}

$\mathrm{CI}=$ Confidence interval, $\mathrm{OR}=$ Odds ratio

\section{Analysis of attitude and practice according to education and status}

Respondents with university-level education were more likely to be familiar with the determinant variables of attitude and practice than school and college respondents (Table-10). They heard of rabies, vaccinated their pets/community dogs against rabies, were familiar with the vaccination/ABC campaign for FRD, sought medical care when bitten by rabid animals, practiced first aid, and also equally used soap water to wash bite-wound by either of the education levels. Besides, respondents from the upper/middle class were more likely to be familiar with the attitudes and practices of rabies than their counterparts. They heard of rabies, vaccinated their pets/community dogs against rabies, were familiar with the vaccination/ ABC campaign for FRD, sought medical care when bitten by rabid animals, did first aid practice, and used soap water to wash bite-wound. This result highlights that respondents with higher education and higher social status followed the standard practices and had better attitudes toward rabies than their counterparts.

\section{Discussion}

This study aimed to comprehend the knowledge, attitudes, and practices of rabies among the communities of five developmental regions in Nepal. To the best of our knowledge and understanding, this was the first large-scale KAP study on rabies conducted in Nepal. This study has few limitations, such as non-random selection of respondents due to topography, the distribution of houses, and the unwillingness of residents to participate. However, the sample population had similar demographic characteristics similar to that of the general Nepalese population. The current study has demonstrated statistically significant differences in knowledge, attitude, and practice of respondents and has identified several knowledge gaps.

\section{Knowledge}

This was surprising given the fact that all categories of respondents had very less knowledge about the cause of rabies. About $7 \%$ of the 275 participants answered correctly about the cause of rabies in India. This might be due to a higher level of education and awareness level of Indian community toward rabies [14]. However, this study was inconsistent with Sri Lanka's study [13]. They reported that $86.2 \%$ of the respondents knew that rabies was caused by microorganisms and spread by dogs, which was found similar to an earlier study done in Gujarat [15]. Their findings 
Available at www.veterinaryworld.org/Vol.14/April-2021/18.pdf

Table-9: Association of gender and age and the responses relating to attitude and practices about rabies.

\begin{tabular}{|c|c|c|c|c|c|c|c|c|c|}
\hline \multirow[t]{2}{*}{ Variables } & \multirow[t]{2}{*}{ Number } & \multicolumn{2}{|r|}{ Gender } & \multirow[t]{2}{*}{$\chi^{2}$ value } & \multirow[t]{2}{*}{ p-value } & \multicolumn{2}{|r|}{ Age } & \multirow[t]{2}{*}{$\chi^{2}$ value } & \multirow[t]{2}{*}{ p-value } \\
\hline & & Male & Female & & & $\leq 35$ & $\geq 36$ & & \\
\hline \multicolumn{4}{|l|}{ Hear of rabies } & 19.85 & $<0.001$ & & & 36.72 & $<0.001$ \\
\hline Yes & 4672 & 2375 & 2297 & & & 2976 & 1696 & & \\
\hline No & 328 & 125 & 203 & & & 154 & 174 & & \\
\hline OR $(95 \% \mathrm{CI})$ & & 1.0 & $0.60(0.47-0.75)$ & & & 1.0 & $0.50(0.40-0.63)$ & & \\
\hline \multicolumn{4}{|c|}{ Vaccination of own pets/community dogs against rabies } & 2.54 & 0.11 & & & 147.08 & $<0.001$ \\
\hline Yes & 3353 & 1703 & 1650 & & & 2294 & 1059 & & \\
\hline No & 1647 & 797 & 850 & & & 836 & 811 & & \\
\hline OR $(95 \% \mathrm{CI})$ & & 1.0 & $0.91(0.81-1.02)$ & & & 1.0 & $0.48(0.42-0.54)$ & & \\
\hline \multicolumn{4}{|c|}{ Familiarity with vaccination $/ A B C^{a}$ campaigns for $F_{R D}$} & 6.67 & 0.01 & & & 36.11 & $<0.001$ \\
\hline Yes & 1294 & 687 & 607 & & & 720 & 574 & & \\
\hline No & 3706 & 1813 & 1893 & & & 2410 & 1296 & & \\
\hline OR $(95 \% \mathrm{CI})$ & & 1.0 & $0.85(0.75-0.96)$ & & & 1.0 & $1.48(1.30-1.69)$ & & \\
\hline \multicolumn{4}{|c|}{ Medication practice when bite by rabid animals/wild lives } & 1.49 & 0.22 & & & 164.71 & $<0.001$ \\
\hline Seek local healer & 1427 & 694 & 733 & & & 695 & 732 & & \\
\hline Seek medical care & 3573 & 1806 & 1767 & & & 2435 & 1138 & & \\
\hline OR $(95 \% \mathrm{CI})$ & & 1.0 & $0.93(0.82-1.05)$ & & & 1.0 & $0.44(0.39-0.50)$ & & \\
\hline \multicolumn{4}{|c|}{ First aid practice if bitten by rabid animals } & 0.52 & 0.47 & & & 328.01 & $<0.001$ \\
\hline Yes & 3595 & 1809 & 1786 & & & 2529 & 1066 & & \\
\hline No & 1405 & 691 & 714 & & & 601 & 804 & & \\
\hline OR $(95 \% \mathrm{CI})$ & & 1.0 & $0.96(0.84-1.08)$ & & & 1.0 & $0.32(0.28-0.36)$ & & \\
\hline \multicolumn{4}{|c|}{ First aid materials in practice } & 0.04 & 0.84 & & & 138.07 & $<0.001$ \\
\hline Soap water & 3079 & 1543 & 1536 & & & 2123 & 956 & & \\
\hline Others* & 1921 & 957 & 964 & & & 1007 & 914 & & \\
\hline OR $(95 \% \mathrm{CI})$ & & 1.0 & $0.99(0.88-1.11)$ & & & 1.0 & $0.50(0.44-0.56)$ & & \\
\hline
\end{tabular}

*Herbal products or traditional methods, anti-birth control, ${ }^{\mathrm{b}}$ Free-roaming dog. $\mathrm{CI}=$ Confidence interval, $\mathrm{OR}=\mathrm{Odds}$ ratio

Table-10: Association of education and socio-economic status and the responses relating to attitude and practices about rabies.

\begin{tabular}{|c|c|c|c|c|c|c|c|c|c|}
\hline \multirow[t]{2}{*}{ Variables } & \multirow[t]{2}{*}{ Number } & \multicolumn{2}{|r|}{ Education } & \multirow[t]{2}{*}{$\chi^{2}$-value } & \multirow[t]{2}{*}{ p-value } & \multicolumn{2}{|c|}{ Socio-economic status } & \multirow[t]{2}{*}{$\chi^{2}$-value } & \multirow[t]{2}{*}{ p-value } \\
\hline & & $\begin{array}{l}\text { School/ } \\
\text { College }\end{array}$ & University & & & Lower & Upper/Middle & & \\
\hline \multicolumn{4}{|l|}{ Hear of rabies } & 35.46 & $<0.001$ & & & 172.8 & $<0.001$ \\
\hline Yes & 4672 & 3619 & 1053 & & & 2441 & 2231 & & \\
\hline No & 328 & 300 & 28 & & & 294 & 34 & & \\
\hline OR $(95 \% \mathrm{CI})$ & & 1.0 & $3.10(2.13-4.70)$ & & & 1.0 & $7.87(5.57-11.48)$ & & \\
\hline \multicolumn{4}{|c|}{ Vaccination of own pets/community dogs against rabies } & 41.45 & $<0.001$ & & & 38.08 & $<0.001$ \\
\hline Yes & 3353 & 2540 & 813 & & & 1732 & 1621 & & \\
\hline No & 1647 & 1379 & 268 & & & 1003 & 644 & & \\
\hline OR $(95 \% \mathrm{CI})$ & & 1.0 & $1.64(1.41-1.92)$ & & & 1.0 & $1.46(1.29-1.64)$ & & \\
\hline \multicolumn{4}{|c|}{ Familiarity with vaccination/ABCa campaigns for $F R D^{b}$} & 165.96 & $<0.001$ & & & 148.43 & $<0.001$ \\
\hline Yes & 1294 & 850 & 444 & & & 520 & 774 & & \\
\hline No & 3706 & 3069 & 637 & & & 2215 & 1491 & & \\
\hline OR $(95 \% \mathrm{CI})$ & & 1.0 & $2.52(2.18-2.90)$ & & & 1.0 & $2.21(1.94-2.52)$ & & \\
\hline \multicolumn{4}{|c|}{ Medication practice when bite by rabid animals/wild lives } & 14.77 & $<0.001$ & & & 47.39 & $<0.001$ \\
\hline Seek local healer & 1427 & 1169 & 258 & & & 890 & 537 & & \\
\hline Seek medical care & 3573 & 2750 & 823 & & & 1845 & 1728 & & \\
\hline OR $(95 \% \mathrm{CI})$ & & 1.0 & $1.36(1.16-1.59)$ & & & 1.0 & $1.55(1.37-1.76)$ & & \\
\hline \multicolumn{4}{|c|}{ First aid practice if bitten by rabid animals } & 176.38 & $<0.001$ & & & 292.23 & $<0.001$ \\
\hline Yes & 3595 & 2644 & 951 & & & 1696 & 1899 & & \\
\hline No & 1405 & 1275 & 130 & & & 1039 & 366 & & \\
\hline OR $(95 \% \mathrm{CI})$ & & 1.0 & $3.52(2.91-4.30)$ & & & 1.0 & $3.18(2.78-3.64)$ & & \\
\hline \multicolumn{4}{|c|}{ First aid materials in practice } & 0.002 & 0.96 & & & 138.12 & $<0.001$ \\
\hline Soap water & 3079 & 2414 & 665 & & & 1483 & 1596 & & \\
\hline Others* & 1921 & 1505 & 416 & & & 1252 & 669 & & \\
\hline OR $(95 \% \mathrm{CI})$ & & 1.0 & $1.00(0.87-1.14)$ & & & 1.0 & $2.01(1.79-2.27)$ & & \\
\hline
\end{tabular}

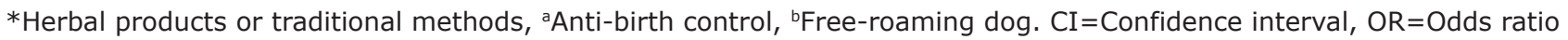

indicated higher level of awareness and knowledge in the respective communities.

About understanding of ways of disease transmission, the response (ranged from 58.68 to $68.35 \%$ ) had identified the dog as a possible vector for rabies transmission. However, the rest of population responded in a mixed, but minimal way such as wildlife, rodents, and cats, were identified as vehicles for rabies transmission. These findings were similar to that of a study done in Ethiopia [16]. According 
to their study, high school respondents $(58 \%)$ and higher education respondents $(73 \%)$ positively responded toward ways of transmission and clinical symptoms. Conversely, this finding is lower than the studies conducted elsewhere in Tanzania [17] and in Namibia [18]. Our study obtained that a large segment of the population was completely unaware of the mode of transmission, which could be considered a significant knowledge gap. Such gaps in the knowledge series reflect the inconsistent awareness in all the age groups and genders [19]. The similar nature of the knowledge gap about the cause, ways of transmission, and clinical manifestation were also reported in Bhutan [20]. The parallel results between these two countries might be due to similar cultural beliefs toward the animals and similar education levels of the communities in both countries.

The response received from all groups for the prescribed clinical signs (altered personality, salivation, hydrophobia, and aerophobia) was lower than 50\%. The results highlighted that the level of knowledge on clinical symptoms was deficient compared to other studies performed elsewhere in the world. One study in Ethiopia described that over $73 \%$ of participants were familiar about clinical symptoms of rabies [21]. These vast differences might be due to the intervention program administered by national and international health agencies in Ethiopia. In recent times, international agencies for rabies control programs are more focused in African regions than the Asian countries. The results suggest that there is a strong need of community awareness about rabies clinical signs.

Regarding the treatment of rabies, both males and females were less knowledgeable about the rabies treatment and its availability. The Sri Lankan study reported that above $93 \%$ of the community, mainly female participants, were well informed about the rabies treatment and prevention procedures [22]. This might be due to multiple interventions in rabies control programs in Sri Lanka, and such activities were lacking in Nepal. The respondents with university-level education were more likely to know the rabies treatment and its availability of treatment of rabies than their counterparts. Similarly, we observed that the upper/middle class was more knowledgeable about the treatment of rabies than the lower social class. Closer examination of the results revealed that the participants with a better level of education and higher social status had better knowledge about rabies treatment and its availability. Thus, participants from lower social strata and lower education could be risk factors for disease control. This finding strongly agreed with the findings of Tiwari et al. [23]. The high level of knowledge about rabies treatment in higher education and upper-class populations might be due to their access to multiple information sources such as government campaigns, activities of non-profits organizations working toward $\mathrm{ABC}$ and rabies control, and mass media [22]. This also applies to the Nepalese context. Our study further tied well with the findings of Ntampaka et al. [24]. They also reported similar observations that the higher level of education might have helped participants to understand the treatment methods and their availability in their area.

For the fatality of rabies, another variable of the knowledge, the female population was less likely to know about the outcome of rabies compared to their counterparts. Similarly, the old age group was found to have less knowledge of rabies fatality. This finding was consistent with the reported from Sri Lanka[13]. However, this study's results were in contrast with the previous study performed in a community of Tanzania [25]. Likewise, the upper/middle-class respondents were better informed about rabies' fatality than the lower social status group. They indicated the post-exposure prophylaxis (PEP) and use of rabies immunoglobulin (RIG) in the case of rabies suspected animal bites.

Concerning knowledge on rabies preventive measures, the female population was found to have less knowledge than male participants. In the same way, the analysis revealed that the older age $(\geq 36$ years) was less likely to know preventive measures. This study agreed with previous studies conducted elsewhere [26]. On the contrary to our findings, the previous studies from India [27,28] reported that female and older age populations were more knowledgeable than their counterparts. The country level's differences might be due to their awareness priorities in the community population.

Likewise, the participants with university degrees displayed the higher level of knowledge than college and high school level students. In the same way, upper-class respondents responded well about the preventive measures of rabies than the lower social status group. This finding was comparable with the findings of the studies conducted elsewhere in Sri Lanka and India $[22,29]$. Both studies reported a similar observation regarding knowledge and prevention. This might be attributable to the high awareness and educational level of participants. We also found good agreement when comparing our results to other studies [30]. This study explained that the educated population and people with a high standard of living were more aware of rabies and vaccinated their pets because of their excellent education and financial status.

\section{Attitude and practice}

This section highlights the community responses about people's attitudes and behavioral practices regarding rabies. The respondents were interviewed to assess if they have heard about rabies, vaccinated their pets/strays, healthcare beliefs in case of dog bites, first aid practices, and type of first aid materials they preferred to use.

The majority of both genders responded that they have heard about the disease. This finding corresponded with the previous studies in Bhutan $[13,20]$. 
Both male and female respondents were almost equally aware of the rabies vaccination practice. This response of the participants indicated that they had a moderate level of information about the vaccination practice that could protect animals or humans from rabies. This might be due to the recent efforts on rabies control initiated by non-profit organizations and volunteer organizations in Nepal. Similar conclusions were made by the previous studies conducted in Sri Lanka and India $[13,29]$. Concerning the age group respondents about attitude and practice towards rabies, the people above 36 years old were less likely to know about rabies. These findings were compatible with the findings of the previous studies performed elsewhere in Sri Lanka and Bhutan [20,22]. They mentioned that the younger generation was much smarter than the age group above 40 years old because of their education, social contacts, and access to media and technology. This study went beyond the previous study conducted in Tanzania [17]. The majority of the younger age group (96\%) of the test population had heard about rabies.

The sample population in the category of higher education and higher level of social status corresponded positively with the attitude and practice variables. University-level education and high social status respondents have heard of rabies. These findings were similar to that of a study done in Ethiopia [16]. According to their study, high school respondents (58\%), higher education respondents $(83 \%)$, and upper/middle class of people in the society positively responded that they have heard about rabies. Conversely, this finding was lower than the studies conducted elsewhere in Tanzania [17] and in Ethiopia [31]. However, both studies agreed with the participants' response that the attitude and practice toward rabies were higher with the advanced level of education and class of the society [32].

Regarding health-seeking behavior in dog bites, our study revealed that the male population is more likely to contact the medical facilities in case of dog bites. More recent studies demonstrated higher proportion (84\%) of the male respondents in India [27], $97 \%$ of the males in Bali, Indonesia [33] and $94 \%$ in Philippines [30] used to go to the hospital in case if they got the dog bites. The medical-seeking behavior in neighboring countries seemed to be higher than Nepal. It might be due to the higher level of knowledge, education, and financial status of those countries. Moreover, in our study, it was quite a surprise to find that some respondents in both genders used to go to the local healers for a dog bite treatment instead of hospitals. Few of them preferred to use herbal products rather than consulting medics. Most of the time, these herbal products cause harmful effects though they contain a certain amount of medicinal value [34]. We suggested that the medical-seeking behavior in the female population was lower than the male respondents. The traditional practices to treat the dog bite were superstitious and needed to be corrected as soon as possible. This conservative belief could be a risk factor in controlling the disease in a community. Similarly, the older age group was less likely to be interested in health-seeking behavior for the dog bite. This finding was in close agreement with other studies done elsewhere in Tanzania [25] and India [35]. Tanzanian study revealed that only $5 \%$ of the sample population used to go to the hospital for the treatment, and only $20.4 \%$ of the respondents were aware of the proper consultation and medical care. In this study, a small number of the respondents preferred to take treatment services from the local healers or apply herbal products over the wound including use of salts, spices, turmeric powder, chili powder, and plant materials, that were not scientifically recommended. The use of such a practice was always life-threatening [1]. The use of soap water, PEP, and infiltration of RIG around the bite could prevent human rabies [1]. However, in this study, over 60 years $(84.33 \%)$ sample population preferred to go to local healers to manage the dog bites. This unscientific practice among old age people could be due to their low level of education and awareness.

In response to first aid practice, both genders were likely to have equal know-how about the practices. They used soap water to clean the dog bite wound. However, a limited number of respondents preferred to consult the local healer and applied the herbal products and spices as a substitute for the first aid. Washing the dog bite wound with soap water has been strongly recommended [1] Nepalese participants' response was relatively better than the previous reports found in Rwanda, Tanzania, and India, Rwanda (20.4\%), Tanzania (5\%), and India (43.07\%) [24,25,35]. Therefore, the study suggested that awareness and educational programs were required in the communities to control rabies. Use of herbal plants and other ingredients was not recommended, and could not replace the standard first aids.

In the same way, the study demonstrated that the older respondents had low-level awareness on first aid and their use. Our findings were in contrast to the previous study from Gujarat [12]. They observed a significantly higher number of people in the older age group practicing the first aid with the recommended materials (soap water) or other detergents such as iodine constituents or according to their availability. A similar study in India [36] showed that a majority of participants, including senior citizens, would practice the recommended procedures (soap water) to clean the wound. This might be due to the differences in the community KAP level of both countries' communities. Indian communities were more advanced in terms of education and financial status than Nepalese society, which could have led them to understand rabies control practices better. However, in our study, the older group was more familiar with the $\mathrm{ABC}$ program conducted by government or non-profit organizations in 
their area. The older group might have received this positive perception through government agencies since the government officials made contact with senior residents in the village to get their support to conduct the $\mathrm{ABC}$ and vaccination programs in the communities.

Similarly, respondents (upper social class) were found to practice cleaning the wound using soap water or detergents. Other studies recorded that the KAP with rabies is far better in urban residents than rural communities [24]. A better understanding of rabies knowledge in the upper-class people and higher education level may be due to their education, social contact, and self-awareness level [37]. Similar observations were also reported from Ethiopia [26].

Likewise, attitude and practice about the vaccination against rabies, the analysis revealed that the older participants were less likely to practice vaccination in animals (dogs). This finding was in line with the finding of a study reported in the Philippines that the younger group was more aware and practiced the vaccination program in the owned or stray population of dogs [30]. This might be due to the opportunity the younger age people receive, such as interacting with public hearings/meetings, reading newspapers, or accessing online information [13]. In a similar fashion, higher education and the higher socio-economic group were found to vaccinate their pets/community dogs against rabies more regularly than the lower level of education and social status group. This study has shown that the community KAP level is subtle in Nepal except in the respondents with higher education and social status. There is also a significant knowledge gap in risk of rabies, its cure, transmission ways, symptoms, and post-bite management issues.

\section{Conclusion}

This analysis leads to some useful conclusions. The KAP level was slightly higher in men and people with higher education and socio-economic status than their counterparts. However, most of the participants were unaware of disease transmission methods, clinical symptoms, and causative factors. Similarly, a significant population also prefers to consult traditional healers and use local remedies over using medical facilities to treat dog bites injuries. Hence, the most relevant conclusions were that there was a need for social awareness programs targeting females, school and college-level students, older age groups, and economically marginalized communities to control rabies in communities. The awareness materials needed to focus on areas such as the risk of rabies, ways of transmission, the importance of first aid, health-seeking behavior following animal bites injuries and practice preventive measures for their pets and community dogs around them.

\section{Authors' Contributions}

PP and TR conceived the study plan and prepared the manuscript. AY and TNB analyzed the data.
RB participated in data collection. All authors read and approved the final manuscript.

\section{Acknowledgments}

The authors are grateful to the Faculty of Veterinary Medicine, Kasetsart University, Thailand, for providing funding and intellectual support to this study.

\section{Competing Interests}

The authors declare that they have no competing interests.

\section{Publisher's Note}

Veterinary World remains neutral with regard to jurisdictional claims in published map and institutional affiliation.

\section{References}

1. World Health Organization. (2018) Zero by 30: The Global Strategic Plan to End Human Deaths from DogMediated Rabies by 2030. Available from: https://www. who.int/rabies/resources/9789241513838/en. Retrieved on 6-11-2020.

2. Kaltungo, B.Y., Audu, S.W., Salisu, I., Okaiyeto, S.O. and Jahun, B.M. (2018) A case of rabies in a Kano brown doe. Clin. Case Rep., 6(11): 2140-2143.

3. Fooks, R.R., Cliquet, F., Finke, S., Freuling, C., Hemachudha, T., Mani, R.S., Müller, T., Nadin-Davis, S., Picard-Meyer, E., Wilde, H. and Banyard, A. (2017) Rabies. Nat. Rev. Dis. Primers, 3: 17091.

4. Knobel, D.L., Cleaveland, S., Coleman, P.G., Fèvre, E.M., Meltzer, M.I., Miranda, M.E.G., Shaw, A., Zinsstag, J. and Meslin, F.X. (2005) Re-evaluating the burden of rabies in Africa and Asia. Bull. World Health Organ., 83(5): 360-368.

5. Wu, X., Hu, R., Zhang, Y., Dong, G. and Rupprecht, C.E. (2009) Reemerging rabies and lack of systemic surveillance in People's Republic of China. Emerg. Infect. Dis., 15(8): 1159-1164.

6. Gongal, G. and Wright, A.E. (2011) Human rabies in the WHO Southeast Asia region: Forward steps for elimination. Adv. Prev. Med., 2011: 383870.

7. Tenzin, T., Ward, M.P. and Dhand, N. (2012) Epidemiology of Rabies in Bhutan: GIS Based Analysis. Available from: https://www.researchgate.net/publication/296050137_epidemiology and control of rabies in bhutan. Retrieved on 6-11-2020.

8. Karki, S. and Thakuri K.C. (2010) Epidemiological situation of animal rabies and its control strategy in Nepal. In: Proceedings of the $9^{\text {th }}$ Conference of Nepal Veterinary Association. Kathmandu. p105-110. Available from: http:// www.docstoc.com/docs/72179558/epidemiology-of-rabies-in-nepal. Retrieved on 6-11-2020.

9. Acharya, K.P., Karki, S., Shrestha, K. and Kaphle, K. (2019) One health approach in Nepal: Scope, opportunities and challenges. One Health, 8: 100-101.

10. Tenzin, T. and Ward, M.P. (2012) Review of rabies epidemiology and control in South, South East and East Asia: Past, present and prospects for elimination. Zoonoses Public Health, 59(7): 451-467.

11. Tenzin, T., Sharma, B., Dhand, N.K., Timsina, N. and Ward, M.P. (2010) Reemergence of rabies in Chhukha District, Bhutan, 2008. Emerg. Infect. Dis., 16(12): 1925-1930.

12. Laishram, J., Chaudhuri, S., Devi, H.S. and Konjengbam, S. (2016) Knowledge and practice on rabies in an urban community of Manipur, India. J. Evol. Med. Dent. Sci., 5(37): 2234-2236. 
13. Matibag, G.C., Kamigaki, T., Kumarasiri, P.V.R., Wijewardana, T.G., Kalupahana,A.W., Dissanayake, D.R.A., de Silva, D.D.N., Gunawardena, G.S.P., Obayashi, Y., Kanda, K. and Tamashiro, H. (2007) Knowledge, attitudes, and practices survey of rabies in a community in Sri Lanka. Environ. Health Prev. Med., 12(2): 84-89.

14. Joice, Y.S., Singh, Z. and Datta, S.S. (2016) Knowledge, attitude and practices regarding dog bite and its management among adults in rural Tamil Nadu. Int. J. Sci. Res., 5(5): 586-589.

15. Singh, U.S. and Choudhary, S.K. (2005) Knowledge, attitude, behavior and practice study on dog-bites and its management in the context of prevention of rabies in a rural community of Gujarat. Indian J. Community Med., 30(3): 81-83.

16. Hagos, W.G., Muchie, K.F., Gebu, G.G., Mezgebe, G.G., Reda, K.A. and Dachew, B.A. (2020) Assessment of knowledge, attitude and practice towards rabies and associated factors among household heads in Mekelle city, Ethiopia. BMC Public Health, 20(57): 1-7.

17. Sambo, M., Lembo, T., Cleaveland, S., Ferguson, H.M., Sikana, L., Simon, C., Urassa, H. and Hampson, K. (2014) Knowledge, attitudes and practices (KAP) about rabies prevention and control: A community survey in Tanzania. PLoS. Negl. Trop. Dis., 8(12): e3310.

18. Haimbodi, F., Mavenyengwa, R. and Noden, B.H. (2014) Knowledge and practices of residents in two north Namibian towns with regard to rabies and pet care. S. Afr. J. Infect. Dis., 29(4): 141-146.

19. Devleesschauwer, B., Aryal, A., Sharma, B.K., Ale, A., Declercq, A., Depraz, S., Gaire, T.N., Gongal, G., Karki, S., Pandey, B.D., Pun, S.B., Duchateau, L., Dorny, P. and Speybroeck, N. (2016) Epidemiology, impact and control of rabies in Nepal: A systematic review. PLoS Negl. Trop. Dis., 10(2): e0004461.

20. Rinchen, S., Tenzin T., Hall, D., Van, D.M.F., Sharma, B., Dukpa, K. and Cork, S. (2019) A community-based knowledge, attitude, and practice survey on rabies among cattle owners in selected areas of Bhutan. PLoS Negl. Trop. Dis., 13(4): e0007305.

21. Rupprecht, C., Kuzmin, I. and Meslin, F. (2017) Lyssaviruses and rabies: Current conundrums, concerns, contradictions and controversies. F1000Res., 6: 184

22. Matibag, G.C., Ohbayashi, Y., Kanda, K., Yamashina, H., Kumara, W.B., Perera I.N.G., de Silva, D.N., Gunawardena, G.S.P., Jayasinghe, A., Ditangco, R.A. and Tamashiro, H. (2009) A pilot study on the usefulness of information and education campaign materials in enhancing the knowledge, attitude and practice on rabies in rural Sri Lanka. J. Infect. Dev. Ctries., 3(1): 55-64.

23. Tiwari, H.K., Robertson, I.D., O'Dea, M. and Vanak, A.T. (2019) Knowledge, attitudes and practices (KAP) towards rabies and free roaming dogs (FRD) in Panchkula district of north India: A cross-sectional study of urban residents. PLoS Negl. Trop. Dis., 13(4): e0007384.

24. Ntampaka, P., Nyaga, P.N., Niragire, F., Gathumbi, J.K. and Tukeim, M. (2019) Knowledge, attitudes and practices regarding rabies and its control among dog owners in Kigali city, Rwanda. PLoS. One., 14(8): e0210044.

25. Sambo, M., Cleaveland, S., Ferguson, H., Lembo, T., Simon, C., Urassa, H. and Hampson, K. (2013) The burden of rabies in Tanzania and its impact on local communities. PLoS Negl. Trop. Dis., 7(11): e2510.

26. Jemberu, W.T., Molla, W., Almaw, G. and Alemu, S. (2013) Incidence of rabies in humans and domestic animals and people's awareness in North Gondar Zone, Ethiopia. PLoS Negl. Trop. Dis., 7(5): e2216.

27. Ohri, P., Jain, K., Kumari, R. and Gupta, S.K. (2016) A study about perception of people regarding animal bite in urban area of Dehradun. J. Evol. Med. Dent. Sci., 5(17): 846-849.

28. Tripathy, R.M., Satapathy, S.P. and Karmee, N. (2017) Assessment of knowledge, attitude and practice regarding rabies and its prevention among construction workers: A cross-sectional study in Berhampur, Odisha. Int. J. Res. Med. Sci., 5(9): 3971-3975.

29. Hossain, M. (2017) Study on knowledge, attitude and practice about rabies and pet animals among school children in Bangladesh. J. Microbiol. Exp., 4(1): 00103.

30. Davlin, S.L., Lapiz, S.M., Miranda, M.E. and Murray, K.O. (2014) Knowledge, attitudes, and practices regarding rabies in Filipinos following implementation of the Bohol rabies prevention and elimination programme. Epidemiol. Infect., 142(7): 1476-1485.

31. Dabuma, T., Kabeta, T. and Mengist, H.M. (2017) Assessment of basic knowledge, attitude and practice of community on rabies and retrospective survey in and around Ambo Town, West Shoa Zone of Ethiopia. J. Med. Microbiol. Diagn., 6(4): 1-4.

32. Widyastuti, M.D.W., Bardosh, K.L., Sunandar, B., C., Basuno, E., Jatikusumah, A., Arief, R.A., Putra, A.A.G., Rukmantara, A., Estoepangestie, A.T.S., Willyanto, I., Natakesuma, I.K.G., Sumantra, I.P., Grace, D., Unger, F. and Gilbert, J. (2015) On dogs, people, and a rabies epidemic: Results from a sociocultural study in Bali, Indonesia. Infect. Dis. Poverty, 4: 30.

33. Tepsumethanon, V., Lumlertdacha, B., Mitmoonpitak, C., Sitprija, V., Meslin, F.X. and Wilde, H. (2004) Survival of naturally infected rabid dogs and cats. Clin. Infect. Dis., 39(2): 278-280.

34. Dhiman, A.K., Thakur, A. and Mazta, S.R. (2017) Treatment seeking behavior of the dog bite patients in Himachal Pradesh, India: A qualitative study. Int. J. Community Med. Public Health, 3(8): 2064-2069.

35. Sangeetha S., Sujatha, K. and William, R.F. (2017) An epidemiological study of animal bites among rural population in Tamil Nadu, India. Int. J. Community Med. Public Health, 3(6): 1413-1418.

36. Pattanayak, S., Malla, T.K., Bara, B.K. and Behera, M.K. (2017) Epidemiological study of animal bite victims and admission in general surgery department, in Southern Odisha: A cross-sectional institutional study. Int. Surg. J., 4(10): 3470-3473.

37. Bihon, A., Meresa, D. and Tesfaw, A. (2020) Rabies: Knowledge, attitude and practices in and around South Gondar, North West Ethiopia. Diseases, 8(1): 5. 